\title{
Colour, water and chlorophyll loss in harvested broccoli (Brassica oleracea L. Italica) under ambient conditions in Pakistan
}

\author{
Muhammad Shakeel $^{1,2}$, Salik Nawaz Khan ${ }^{2}$, Yasar Saleem ${ }^{3}$, Paul J. Burgess ${ }^{4}$ \\ Shazia Shafiq ${ }^{2}$ \\ ${ }^{1}$ Agriculture Research Institute (ARI) Sariab-Quetta, Pakistan \\ ${ }^{2}$ Institute of Agricultural Sciences (IAGS) University of the Punjab, Lahore, Pakistan \\ ${ }^{3}$ Pakistan Council for Scientific and Industrial Research (PCSIR), Lahore, Pakistan \\ ${ }^{4}$ Cranfield University, Cranfield, Bedfordshire, MK43 0AL United Kingdom
}

\begin{abstract}
Broccoli (Brassica oleracea L. Italica) is a nutritious green vegetable containing desirable phytochemicals that is being more widely consumed in Pakistan. However the florets rapidly discolour and wilt after harvest. This study reports the changes in the colour, turgor, weight, visual quality and chlorophyll of harvested broccoli florets after harvest under ambient temperatures of $18 \pm 1{ }^{\circ} \mathrm{C}$ and a relative humidity of $45-62 \%$. There were significant declines in colour, turgor, weight and chlorophyll within the first two days, with a change from "good" to "unacceptable" assessments occurring at day 4 or 5. The level of chlorophyll decreased from $13.47 \mu \mathrm{g} / \mathrm{mg}$ on day 1 to $5.18 \mu \mathrm{g} / \mathrm{mg}$ on day 4 . It is proposed that the green colour and turgor can be retained longer by storing at lower temperatures and higher relative humidities.
\end{abstract}

\section{Introduction}

Broccoli (Brassica oleracea L. Italaia) is a widely-consumed floral green vegetable which has high levels of vitamins, antioxidants, anti-carcinogenic compounds (Nestle, 1998: Ares, 2014) and glucosinolates (Yuan et al., 2010) which have been associated with cancer protection and the reduction of cardiovascular diseases (Talalay et al., 1995: Kushad et al., 1999: Rangkadilok et al., 2002: Vallejo et al., 2003: Ku et al 2013). Broccoli has also been ranked as one of the best inducers of detoxification enzymes in mammals (Dominguez-Perles et al., 2011).

Brocolli can be grown in many parts of Pakistan and it is particularly suited to the cooler temperatures of Balochistan. However retailers and consumers only want broccoli heads that are green and show no surface dehydration. In Pakistan, after harvest it can take one to two days for the broccoli to reach the retailer by which time deterioration has started due to the lack of packaging and postharvest treatment (Nath et al., 2011). With the exception of a few supermarkets, the broccoli heads are kept under ambient conditions until sold or until they become unacceptable. At $20^{\circ} \mathrm{C}$, the final weight of broccoli florets can decrease by $55 \%$ by day 5 (Jia et al., 2009). During storage there is also chlorophyll degradation and a loss of green colour (Yamauchi et al., 1997). For example, Takeda et al. (1993) report an 80-90\% reduction in chlorophyll in broccoli florets within 4 days if stored at $23^{\circ} \mathrm{C}$. Although yellowing can be slowed by storage at lower temperatures (Izumi et al., 1996), the lack of cooling facilities in Pakistan means that significant post-harvest losses remain (Shafiq et al., 2012). 
The objective of this study was to examine the chlorophyll changes and weight loss of broccoli florets grown and stored under ambient conditions in Pakistan. The study should enable retailers and consumers to better understand the conditions affecting the perishability of harvested broccoli florets.

\section{Materials and Methods \\ 2.1 Plant material}

Seedlings of the broccoli variety "Marathon F1", sown in late September 2016 were transplanted after three weeks in a field at the Institute of Agricultural Sciences (IAGS), University of the Punjab, in the Lahore district of Pakistan (31.4950 0N, 74.269 0E).Standard practices like irrigation and weeding were used until the crop was harvested. The florets were harvested 100-110 days after transplanting and were immediately transported to the laboratory where they were cleaned and washed for further analysis.

\subsection{Colour, turgor, weight loss and visual quality}

The floret heads were stored, in three replicates, at a mean room temperature of $18 \pm 1{ }^{\circ} \mathrm{C}$. The quality characteristics of the freshly harvested, washed and dried florets were measured on day 1 and then at daily intervals for up to 10 days.

Colour: The colour of the stored broccoli florets was assessed visually on each sampling day using a non-linear colour rating scale described by Rangadilok et al. (2002). A scale of 1 to 6 was used: 1: green, 2 : traces $(<10 \%$ yellowing), 3: slight yellowing (11-20\%), 4: moderate yellowing (20-30\%), 5: severe (30 -50\%), and 6: waste (>50\% yellowing).

Turgor: the turgidity of the broccoli florets was measured visually on each sampling day using a turgor rating scale based on Winkler et al. (2007). The scale of 1 to 6 was: 1: excellent (turgid), 2: very good (virtually turgid), 3: good, (traces of limpness) 4: fair, (moderate level of limpness) 5: poor/not acceptable (severe limpness-nearly dried), and 6: waste.

Weight loss: harvested florets of a similar size and appearance were weighed to determine the proportional weight loss. The loss of water was expressed as a percentage weight loss as described by Fernández-León (2013) and Serrano et al. (2006).

Visual quality: visual assessments were made on each sampling day of the general appearance of freshness (in a similar way to a consumer) as described by $\mathrm{Ku}$ and Wills (1999), , Jia et al (2009), Yuan et al. (2010) and adopted by Guo et al. (2011) with little modification. The scale of 1 to 6 was: 1: excellent (Brilliant fresh appearance), 2: very good (Fresh appearance), 3: good (Limit of marketability), 4: fair (usable but cannot be marketed), 5: poor/not acceptable, and 6: waste.

\subsection{Chlorophyll content}

Chlorophyll was extracted from the florets using the Standard Operating Procedure (SOP) described by the Scientific Engineering Response and Analytical Services, Environmental Protection Agency of the United States (SERAS 1994) and the procedure adopted by Ku et al., (2013) and Rajlalshkmi and Bano (2015). Briefly the procedure was to take $2 \mathrm{~g}$ of a broccoli floret, which was cut into small pieces, and homogenised with $2 \mathrm{ml}$ of $0.1 \mathrm{~N} \mathrm{NH}_{4} \mathrm{OH}$ extraction solution to form a fine slurry. Plant material adhered to the pestle was washed off using $3 \mathrm{ml}$ of extraction solution, and then $5 \mathrm{ml}$ of $80 \%$ aqueous acetone solution was added. The sample extracts were centrifuged at $1972 \mathrm{rpm}$ for 20 minutes. The supernatant solution was decanted 
and the final volume was brought up to $10 \mathrm{ml}$ using $80 \%$ aqueous acetone. The extracted sample was then analysed using a spectrophotometer operating at wavelengths of 645 and 663 $\mathrm{nm}$. Initially aqueous acetone $80 \%$ was used as a blank to zero the spectrophotometer. The equations reported by Arnon (1949) and Ku et al. (2013) were then used to calculate the levels of chlorophyll a, chlorophyll $\mathrm{b}$ and total chlorophyll.

Chlorophyll a $(\mu \mathrm{g} / \mathrm{mL})=20.2\left(\mathrm{~A}_{645}\right)+8.02\left(\mathrm{~A}_{663}\right)$

Chlorophyll b $(\mu \mathrm{g} / \mathrm{mL})=12.7\left(\mathrm{~A}_{663}\right)-2.69\left(\mathrm{~A}_{645}\right)$

Total chlorophyll $(\mu \mathrm{g} / \mathrm{mL})=22.9\left(\mathrm{~A}_{645}\right)-4.68\left(\mathrm{~A}_{663}\right)$

Where:

$\mathrm{A}_{645}=$ absorbance at a wavelength of $645 \mathrm{~nm}$;

$\mathrm{A}_{663}=$ absorbance at wavelength of $663 \mathrm{~nm}$.

\subsection{Statistical analysis}

A one-way analysis of variance of the means and variance of means and standard deviations of visual quality, colour, turgidity, physiological weight loss and the levels of chlorophyll a and $\mathrm{b}$ and total chlorophyll was completed using STATISTIX 8.1 (2005) Analytical Software. The test of statistical significance was undertaken at a 0.05 level.

\section{Results}

\subsection{Colour, turgor, proportional weight loss, and visual quality}

The colour deterioration of the broccoli florets, stored at $18^{\circ} \mathrm{C}$, started from day 1 with traces of yellowing already present on day 2 (Figure 1). On day 4, there was slight colour deterioration (11-20\% yellowing), but this was considered to be "severe" (30-50\% yellowing) on day 5. On day 6 , the level of discoloration (5.7) was sufficiently great for the florets to be considered as "waste".

A significant decline in turgor was only recorded from day 3 (Figure 1). From "excellent" on day 1 , the level of turgor was still considered to be "good" on day 5 . However on day 6 , the broccoli was considered to have poor turgidity $(>4)$ and it was no longer acceptable for consumption (Figure 1).

There was a steady loss in the weight of the broccoli. There was a weight loss of $7.7 \%$ within the first 24 hours, and by days 5 and 6 the total weight loss was $22.4 \%$ and $27.2 \%$ respectively. By day 10, the florets had lost $41.6 \%$ of their initial weight.

The visual quality of the broccoli florets also declined steadily during the storage period, moving from a "good" rating on day 4 to a "fair" rating on day 5. Florets on day 6 were found "unacceptable" (rating > 5) and on day 7 were brown/yellow and rated as "waste" (Figure 1). 


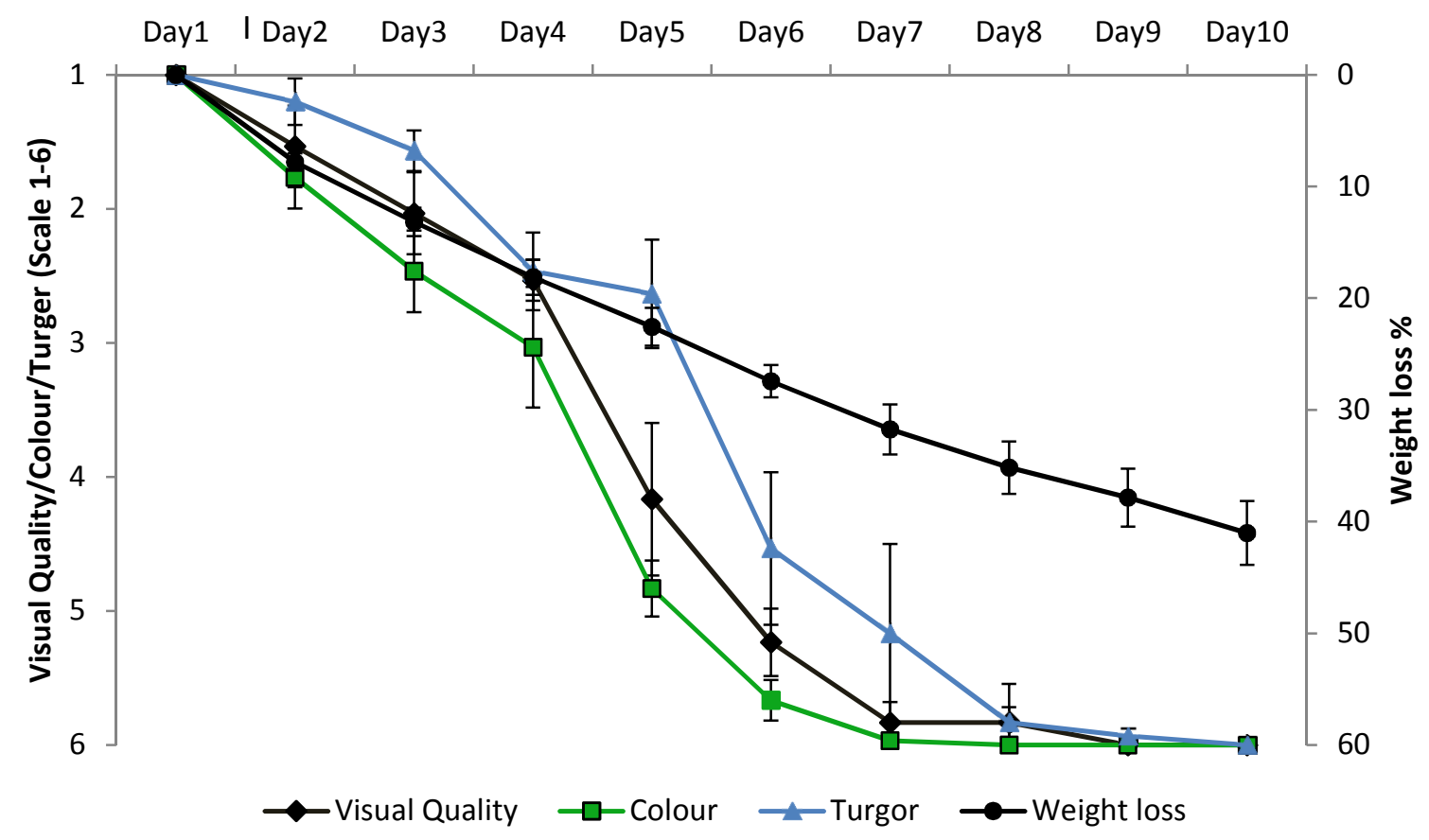

Fig 1. Effect of time from harvest on the colour, turgor, weight loss, and visual quality of broccoli florets stored at $18 \pm 1^{\circ} \mathrm{C}$ and a relative humidity of $45-62 \%$. Values represent the means of three replicates on a rating scale (1-6) $(n=3)$, for colour 1 : green, 2 : traces ( $<10 \%$ yellowing), 3 : slight yellowing (11$20 \%), 4$ : moderate yellowing (20-30\%), 5 : severe (30-50\%), and 6: waste (>50\% yellowing), for turgor 1: excellent (turgid), 2: very good (virtually turgid), 3: good, (traces of limpness) 4: fair, (moderate level of limpness) 5: poor/not acceptable (severe limpness-nearly dried), and 6: waste, for visual quality 1 : excellent (Brilliant fresh appearance), 2: very good (Fresh appearance), 3: good (Limit of marketability), 4: fair (usable but cannot be marketed), 5: poor/not acceptable, and 6: waste and weight loss as cumulative \% loss in weight. Vertical bars represent the standard deviation of the means.

\subsection{Chlorophyll content}

The chlorophyll $a$ and $b$ content of the broccoli florets declined $(p<0.05)$ during the seven days after harvest (Figure 2). The level of chlorophyll a, declined from $13.47 \mu \mathrm{g} / \mathrm{mg}$ on day 1 to $5.18 \mu \mathrm{g} / \mathrm{mg}$ on day 4 . The level of chlorophyll $\mathrm{b}$, declined during the same period from 7.31 to $2.12 \mu \mathrm{g} / \mathrm{mg}$. The total content of chlorophyll, as the sum of these two values, showed a similar decline. The total decrease in the level of chlorophyll a, across the seven days was $74 \%$, whilst the decline in chlorophyll b, was $82 \%$. 


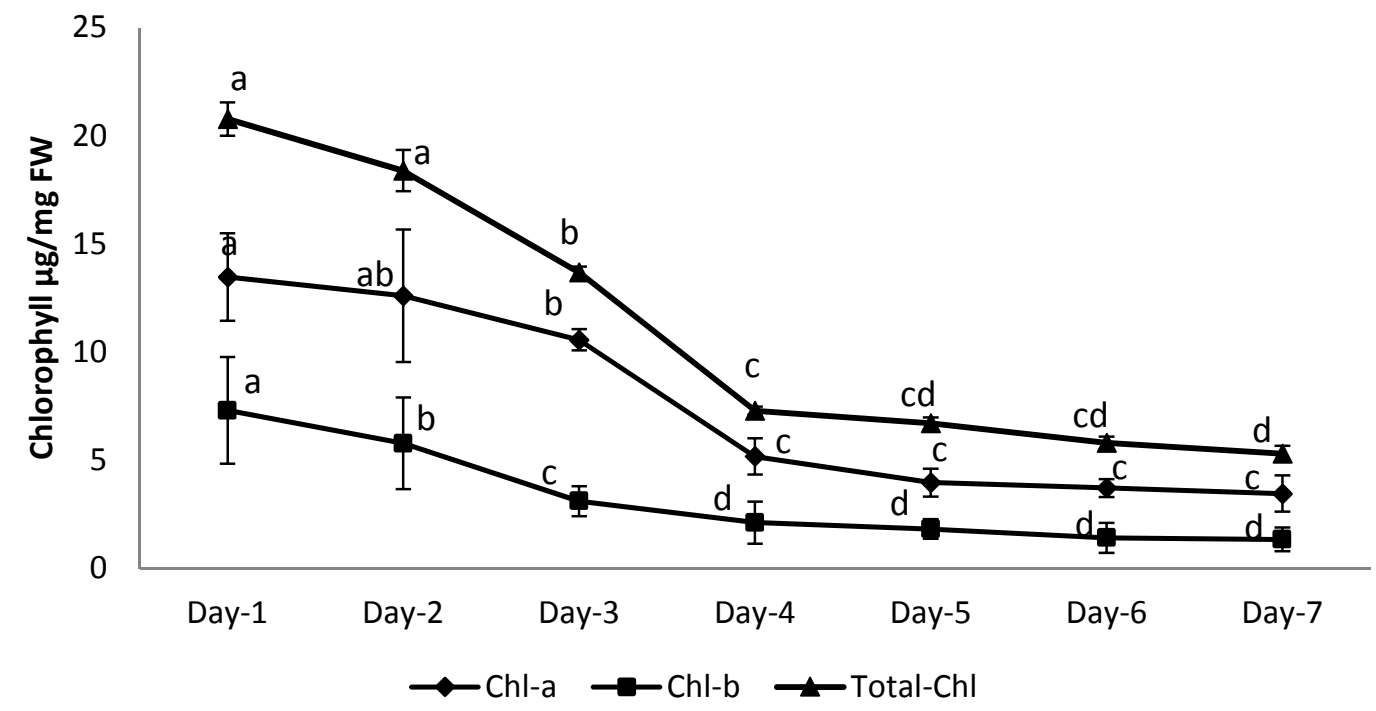

Fig 2. Effect of storage time on the content of chlorophyll $a, b$ and total chlorophyll of broccoli florets stored at $18 \pm 1^{\circ} \mathrm{C}$ and a relative humidity of $45-62 \%$. Values represent the means of three replicates $(n=3)$. Vertical bars represent the standard deviation of the means. Values with different letters are significantly different $\mathrm{P}<0.05$.

\section{Discussion}

The results show that the colour, visual quality, turgor and levels of chlorophyll in broccoli deteriorated quickly after harvest at the ambient air temperature of $18^{\circ} \mathrm{C}$ and a relative humidity of $45-62 \%$ found in Pakistan. Similar results have been reported by Hansen et al. (2001), Xu et al. (2006), and Jia et al., (2009).

The most important commercial quality index for broccoli is its green colour, being the primary determinant of quality for the consumer. The green colour of the broccoli was assessed in terms of subjective visual assessment on a six-point scale and in terms of the chlorophyll content. In our study, severe yellowing (up to 50\%) was reported on day 5 at which point the broccoli would be unacceptable to consumers. A similar rate of decline has been reported by Jin et al. (2015) and Nath et al. (2011).

The green colour of the broccoli is due to the presence of chlorophyll a and chlorophyll $\mathrm{b}$ which were 13.47 and $7.31 \mu \mathrm{g} / \mathrm{mg}$ on day 1 respectively. The level of chlorophyll decreased sharply between day 3 and day 4 (Figure 2), at an earlier stage than the greatest decline in the visual assessments. Although the chlorophyll contents were measured on a fresh weight basis, the decline in water content (Figure 1) is relatively consistent during the sampling period. The breakdown of chlorophyll has two key phases: an initial phase where chlorophyll is converted into non-green breakdown products within chloroplasts and a second phase where the nongreen catabolites move from the chloroplasts to the vacuole (Christ and Hortisteiner 2013). It is arguable that the chlorophyll analysis is more objective in that it is based on a linear scale, whereas the six-point colour scale is non-linear with the move from the midpoint of " 3 " to "4" representing a $10 \%$ change, that from " 4 " to " 5 " a $15 \%$ change in colour, and that from the midpoints of " 5 " to " 6 " a $35 \%$ change. The process of senescence and yellowing in plants is related to the action of the plant's defence system and the action of antioxidants and enzymes such as superoxide dismutase, catalase and peroxidase (Han et al., 2006). High temperatures and low relative humidity can slow down the activities of superoxide dismutase, catalase and peroxidase, eventually lowering the oxygen radical production that leads to the yellowing of 
broccoli (Singh and Dwivedi, 2008: Yuan 2010). Whilst temperature and humidity control are likely to be the main methods to delay yellowing, some studies have shown that post-harvest treatment with 1-MCP can also reduce the pace of yellowing in broccoli florets at $20^{\circ} \mathrm{C}$ (Yuan et al., 2010: Sabir, 2012).

The broccoli florets lost $20 \%$ of the initial weight after four days and $40 \%$ after ten days. This decline in water content was also monitored using a 1-6 turgor scale which declined from excellent" (1) on day 1 to "good" (2.9) at day 5 and "waste" (6.0) on day 9. A similar weight loss of $42 \%$ from broccoli florets under ambient conditions has been reported by Nath et al., (2011). At $20^{\circ} \mathrm{C}$, which is $2^{\circ} \mathrm{C}$ higher than the temperature in this experiment, Jia et al. (2009) reported a 55\% loss by day 5 . There may also have been differences in the relative humidity, which was $45-62 \%$ in our study. Reducing the saturation vapour deficit experienced by the stored broccoli (either by reducing the temperature or increasing the humidity) would likely have reduced the weight loss. For example Toivonen and Forney (2004) and Jones et al., (2006) recommend a relative humidity of $80-100 \%$ for broccoli storage. In a different study, Jia et al., (2009) stored broccoli in three types of bags: one without holes, one with two microholes and a third one with four macroholes. They found that shelf life increased in those florets stored in the bag with no holes and related this to the high relative humidity.

The visual assessment of quality is likely to include subjective assessment of both colour and weight loss. This quality assessment was "acceptable" up to day 4, before declining to "unacceptable" on day 5. This threshold appears to be more related to the change in colour than the level of turgor.

\section{Conclusion}

The green colour, turgor, weight, and visual quality assessment of broccoli florets declined quickly within five days of harvest, when stored at $18^{\circ} \mathrm{C}$ and a relative humidity of $45-62 \%$. There was also a $60 \%$ decline in the level of chlorophyll within four days of storage. These results suggest that the appropriate time interval for storage, in the case of the stated ambient conditions, is 4-5 days. During this time, there was 23\% loss in broccoli weight compared with that at harvest. Maintaining the harvested crop at low temperatures with low saturation vapour pressure deficits may increase the shelf-life of broccoli.

\section{Acknowledgments}

Authors thank Mr. Mirza Abdul Wahid, Director Agriculture Research, ARI-Quetta Pakistan for his valuable help in statistical analysis and interpretation of results. A laboratory facility for execution of research work was provided by the PCSIR (Pakistan Council for Scientific and Industrial Research) and seeds/germ plasm was provided by the Vegetable Gene Bank, Warwick University UK. Authors thank all of them for their generous cooperation. The study was self-sponsored, however, partly funded by the Institute of Agricultural Sciences, University of the Punjab, Lahore.

\section{References}

Ares, A. M., Nozal, M. J., José L. Bernal, J. L. and Bernal, J., 2014. Optimized extraction, separation and quantification of twelve intact glucosinolates in broccoli leaves. Food Chemistry, 152, 66-74.

Arnon, D. I., 1949. Copper enzymes in isolated chloroplasts. Polyphenoloxidase in Beta vulgaris. Plant Physiology. 24, 1-15. 
Christ, B. and Hörtensteiner, S., 2013. Mechanism and significance of chlorophyll breakdown. Journal of Plant Growth Regulations, 33, 1- 18.

Dominguez-Perles, R., Martinez-Ballesta, M. C., Riquelme, F., Carvajal, M., García- iguera, C. and Moreno, D. A., 2011. Novel varieties of broccoli for optimal bioactive components under saline stress. Journal of the Science of Food and Agriculture, 91, $1638-1647$.

Fernández-León, M. F., Fernández-León, A. M., Lozano, M., Ayuso, M. C. and GonzálezGómez. D., 2013. Different postharvest strategies to preserve broccoli quality during storage and shelf life: Controlled atmosphere and 1-MCP. Food Chemistry, 138, 564573.

Guo, R., Yuan, G., and Wang, Q. (2011). Effect of sucrose and mannitol on the accumulation of health-promoting compounds and the activity of metabolic enzymes in broccoli sprouts. Scientia Horticulturae, 128(3), 159-165

Han, J. H., Tao, W. Y., Hao, H. K., Zhang, B. L., Jiang, W. B., Niu, T. G., et al., 2006.

Physiology and quality responses of fresh-cut broccoli florets pretreated with ethanol vapour. Journal of Food Science, 71(5), 385-389.

Hansen, M. E., Sorensen, H. and Cantwell, M. , 2001. Changes in acetaldehyde, ethanol and amino acid concentrations in broccoli florets during air and controlled atmosphere storage. Postharvest Biology and Technology, 22, 227-237.

Izumi, H., Watada, A. E. and Douglas, W., 1996. Optimum O2 or CO2 atmospheres for storing broccoli florets at various temperatures. Journal of the American Society for Horticultural Science, 121, 127-131.

Jia, C., Xu, C. Wei, J., Yuan, J., Yuan, G., Wang, B. and Wang, Q., 2009. Effect of modified atmosphere packaging on visual quality and glucosinolates of broccoli florets. Food Chemistry, 114, 28-37.

Jin, P., Yao, D., Xu, F., Wang, H., Zheng, Y., 2015. Effect of light on quality and bioactive compounds in postharvest broccoli florets. Food Chemistry, 172, 705-709.

Jones, R. B., Faragher, J. D. and Winkler, S., 2006. Review A review of the influence of postharvest treatments on quality and glucosinolate content in broccoli (Brassica oleracea var. italica) heads. Postharvest Biology and Technology, 41, 1-8

Ku, K. M., Choi, J. H., Kim, H.S., Kushad, M. M., Jeffery, E. H. and Juvik, J. A., 2013. Methyl Jasmonate and I-Methylecyclopropane Treatment Effects on Quinone Reductase Inducing Activity and Post-Harvest Quality of Broccoli. PloS ONE 8(10): e77127. Doi:10.1371/journal. Pone.0077127

Ku, V. V. V., and Wills, R. B. H., 1999. Effect of 1-methylcyclopropene on the storage life of broccoli. Postharvest Biology and Technology, 17(2), 127-132.

Kushad, M. M., Brown, A. F., Kurilich, A. C., Juvik, J. A., Klein, B.P., Wallig, M.A. and Jeffery, E. H., 1999. Variation of glucosinolates in vegetable crops of Brassica oleracea. Journal of Agriculture Food Chemistry, 47, 1541-1548.

Nath, B., Bagchi, L., Misra, K. and Deka, B.C., 2011. Changes in post-harvest phytochemical qualities of broccoli florets during ambient and refrigerated storage. Food Chemistry 127 , $1510-1514$

Nestle, M., 1998. Broccoli sprouts in cancer prevention. Nutrition Reviews, 56, 127-130.

Rajalakshmi and Bano, 2015. Extraction and Estimation of Chlorophyll from Medicinal Plants. Int. J. of Sci. and Res. (IJSR), 13(6), 2319-7064.

Rangkadilok, N., Tomkins, B., Nicolas, M.E., Premier, R.R., Bennett, R.N., Eagling, D.R. and Taylor, P.W.J., 2002. The effect of postharvest and packaging treatments on glucoaphanin concentration in broccoli (Brassica oleracea var. italica). Journal of Agriculture Food Chemistry, 50, 7386-7391. 
Sabir, F. K., 2012. Postharvest quality response of broccoli florets to combined application of 1-methylcyclopropene and modified atmosphere packaging. Agricultural and Food Science, 21(4), 421-429.

Serrano, M., Martinez-Romero, D., Guillen, F., Castillo, S., and Valero, D., 2006. Maintenance of broccoli quality and functional properties during cold storage as affected by modified atmosphere packaging. Postharvest Biology and Technology, 39, 61-68.

SERAS, 1994. Scientific Engineering Response and Analytical Services. Environmental protection Agency United states available at https://clu-in.org/download/ert/2030-R00.pdf

Shafique, S. Majeed, A. R. and Shafique, S., 2012. Cymbopogon citrates: A remedy to control selected Alternaria species. J. of Med. Plants Res. 6(10), 1879-1885

Singh, R. and Dwivedi, U. N., 2008. Effect of Ethrel and 1-methylcyclopropene (1- MCP) on antioxidants in mango (Mangifera indica var. Dashehari) during fruit ripening. Food Chemistry, 111(4), 951-956.

Takeda, Y., Yoza, K. I., Nogata, Y. and Ohta, H.,1993. Effects of storage temperatures on polyamine content of some leafy vegetables. Journal of the Japanese Society for Horticultural Science, 62, 425-430.

Talalay, P., Fahey, J. W., Holtzclaw, W. D., Prestera, T. and Zhang, Y., 1995. Chemoprotection against cancer by Phase II enzyme induction. Toxicological. Letters. 82, 173-179.

Toivonen, P.M.A. and Forney, C., 2004. Broccoli. In: The Commercial Storage of Fruits, Vegetables and Florist and Nursery Stock. USDA, ARS. Agriculture Handbook \#66.

Vallejo, F., Garc`1a-Viguera, C. and Tomás-Barberán, F., 2003. Health promoting compounds in broccoli as influenced by refrigerated transport and retail sale period. Journal of Agriculture Food Chemistry. 51, 3029-3034.

Winkler, S., Faragher, J., Franz, P., Imsic, M., and Jones, R., 2007. Glucoraphanin and flavonoid levels remain stable during simulated transport and marketing of broccoli (Brassica oleracea var. italica) heads. Postharvest Biology and Technology, 43, 89-94.

Xu, C. J., Guo, D. P., Yuan, J., Yuan, G. F. and Wang, Q. M., 2006. Changes in glucoraphanin content and quinone reductase activity in broccoli (Brassica oleracea var. italica) florets during cooling and controlled atmosphere storage. Postharvest Biology and Technology, 42, 176-184.

Yamauchi, N. , Harada, K., and Watada, A. E.,1997. In vitro chlorophyll degradation in stored broccoli (Brassica oleracea L. 6ar. italica Plen.) florets. Postharvest Biology and Technology 12, 239-245.

Yuan, G., Sun, B., Yuan, J., and Wang, Q. ,2010. Effect of 1-methylcyclopropene on shelf life, visual quality, antioxidant enzymes and health-promoting compounds in broccoli florets. Food Chemistry, 118, 774-781. 